\title{
FORMAÇÃO DE PROFESSORES EM TEMPOS DE BNCC: UM OLHAR A PARTIR DO CAMPO DO CURRÍCULO ${ }^{1}$
}

\author{
Formación de profesores en tiempos BNCC: una mirada desde el campo curricular \\ Teacher training in BNCC times: a look from the curriculum field
}

Rita de Cássia Prazeres Frangella*

https://doi.org/10.38117/2675-181X.formov2020.v2i2n4.380-394

\section{RESUMO}

A partir de pesquisa desenvolvida sobre política pública que tem como ação prioritária a formação de professores alfabetizadores em serviço, o Pacto Nacional de Alfabetização na Idade Certa/PNAIC (BRASIL, 2012), tenho discutido o imbricamento das proposições de políticas de formação de professores também como produção curricular. Defende-se outra perspectiva para analisar essa relação: formação e políticas curriculares como articulação em meio à luta por significação na produção de políticas públicas. Argumenta-se que o deslocamento de significantes como formação, currículo, qualidade se articulam na produção de um discurso que significa o investimento na formação de professores como instituintes de políticas curriculares. A investigação infere sobre a produtividade dessa articulação, que se constitui na ambivalência discursiva que torna o político possível. Esse estudo visa discutir os sentidos de currículo e formação que se pretende hegemonizar.

PALAVRAS CHAVE: Formação de professores; Políticas curriculares; Discurso.

\section{RESUMEN}

Basado en una investigación desarrollada en políticas públicas que tiene como acción prioritaria la capacitación de maestros de alfabetización en servicio, el Pacto Nacional de Alfabetización en la Edad Adecuada / PNAIC (BRASIL, 2012), he discutido la superposición de propuestas de políticas para la formación de docentes también como producción curricular. Se defiende otra perspectiva para analizar esta relación: la capacitación y las políticas curriculares como articulación en medio de la lucha por el significado en la producción de políticas públicas. Se argumenta que

\footnotetext{
${ }^{1}$ Desenvolvido a partir de pesquisas financiadas pelo CNPq (Universal, 2018; Bolsa de Produtividade PQ), FAPERJ (Edital Cientista no Nosso Estado) e UERJ (Prociência UERJ)
} 
el desplazamiento de significantes como la capacitación, el currículum y la calidad se articulan en la producción de un discurso que significa inversión en la capacitación docente como institución de políticas curriculares. La investigación infiere la productividad de esta articulación, que constituye la ambivalencia discursiva que hace posible lo político. Este estudio tiene como objetivo discutir los significados del currículum y la capacitación que están destinados a ser hegemonizados.

PALABRAS CLAVE: Formación del profesorado; Políticas curriculares; Discurso.

\begin{abstract}
Based on research developed on public policy that has as a priority action teacher education of literacy in service, the National Pact of Literacy at the Right Age / PNAIC (BRAZIL, 2012), I have discussed the overlapping of policy proposals for the teacher education also as curricular production. Another perspective is defended to analyze this relationship: formation and curricular policies as articulation within the struggle for meaning in public policies design. We argue that the displacement of signifiers such as teacher formation, curriculum, and quality articulate in the production of a discourse that means investment in teacher education as instituting curricular policies. The investigation infers on the productivity of this articulation, which constitutes the discursive ambivalence that makes possible the policy. This study aims at discussing the meanings of curriculum and education that are to be hegemonized.
\end{abstract}

KEYWORDS: Teacher education; Curricular policies; Discourse.

\title{
Políticas curriculares, formação de professores na trajetória de pesquisa: constituindo possibilidades de significar
}

A temática da formação de professores e questões a ela relacionadas mobilizam uma série de pesquisadores sob diferentes ângulos. A partir do campo do currículo tem se produzido análises potentes acerca da formação, na complexa relação que se estabelece na produção de políticas curriculares que produzem efeitos de sentido sobre a docência e a formação de professores, na análise de demandas curriculares para a formação e que enredam um discurso que pretende signifixar (MACEDO, 2016) sentidos de docência, trabalho docente e daí também sua formação. (DIAS E FRANGELLA, 2018)

No campo do currículo, venho desenvolvendo estudos acerca de políticas curriculares que focalizam a formação de professores (FRANGELLA, 2016a; 2019), a partir de programa de formação continuada de grande escopo proposto pelo governo 
Federal, o Pacto Nacional para a Alfabetização na Idade Certa/ PNAIC. Na esteira de desenvolvimento desses estudos, a problematização que proponho não focaliza a proposta curricular que esse programa traz para a formação, mas o analiso como campo de produção curricular tanto para a formação docente quanto para a educação básica, numa intrincada relação em que, ao relacionar política curricular e formação de professores o e conectivo não significa o pareamento ou estabelecimento de binarismos, mas, na perspectiva derridiana com que dialogo, trata-se de uma lógica suplementar que ao suprir a falta adiciona o excesso, como um borramento que subtrai a ideia de limite - é o nãolimite que torna imprecisa e impossível a ideia de presença plena ou lugar originário, o que em outros estudos argumentei como formação e políticas curriculares sob rasura

Assim, com formação e currículo sob rasura, apaga-se a fronteira delimitadora e fixada na medida em que estas são sempre presença/ausência, nunca realizadas totalmente. Essa duplicação, uma espacialização cindida em um entre-tempo, desestabiliza uma pretensa unidade tanto da formação de professores quanto das políticas curriculares (FRANGELLA, 2016b, p.114)

E no desenvolvimento dessa argumentação venho defendendo que é impossível precisar origem ou delimitação do que cabe a cada esfera. Ao contrário, assentada numa perspectiva discursiva que entende as políticas como jogos de linguagem indecidíveis, sempre instáveis, numa ambiguidade constitutiva, evidencia-se o jogo político em torno da significação. Esse jogo se desdobra nas injunções dos significantes currículo, formação, conhecimento, alfabetização, o que tem sido o foco de análise da pesquisa. Observo como políticas curriculares e formação de professores estão imbricadas como esferas de produção de políticas curriculares para educação básica. Assim, questiono ideias correntes que estabelecem uma anterioridade às políticas curriculares que postam as mudanças na formação como secundárias a esses processos; numa lógica etapista, a formação seria um movimento subsequente às políticas curriculares, ou seja, institui-se a formação para se instituir uma política curricular.

Essa perspectiva mantém o que Ball $(1997,2016)$ critica na análise das políticas educacionais que desenvolve, chamando atenção para além da implementação: em sua argumentação destaca os movimentos complexos de elaboração de políticas, que envolve múltiplos atores/contextos e nesse sentido, mais que colocadas em práticas, as políticas são também constituídas no envolvimento/ação desses múltiplos atores/contextos, o que, de outra forma e também em diálogo com o autor, venho defendendo no entendimento de professores-professoras como curriculistas, na produção que fazem do currículo compreendido então com campo de produção cultural, espaço-tempo de negociações que hibridizam discursos, concepções e práticas produzidas nos diferentes contextos que concorrem para sua produção. Assim, políticas curriculares não podem tomar a escola como ponto de referência ou ancoragem apenas, pelo fato de ser também na escola que 
as políticas de currículo se constituem, via disputas e negociações de saberes e poderes que legitimam e hegemonizam provisoriamente sentidos.

\section{Políticas curriculares e formação de professores: que relação?}

A profusão de políticas curriculares produzidas nos últimos anos nos convocam constantemente à discussão acerca do que essas propõem para Educação, para o cotidiano de redes de ensino, nas escolas e a pergunta que vem atrelada: e a formação?

De forma análoga, parece que cada nova proposta se volta para formação como condição necessária para sua plena "implementação". Assim, cria-se um nexo causal simples, de causa e consequência que se repete, e repete... O tic-tac contínuo de um relógio que parece andar sempre na mesma direção de sucessão do tempo, das coisas... Diria Vinícius de Moraes (2010) que o relógio já está cansado de fazer tic-tac dia e noite, noite e dia...

Ainda assim, essa lógica causal parece ditar rumos no campo da formação: uma nova proposta requer uma nova formação adequada a ela... Isso é perceptível nas disposições da Base Nacional Comum Curricular (2017) que focaliza a formação:

Embora a implementação seja prerrogativa dos sistemas e das redes de ensino, a dimensão e a complexidade da tarefa vão exigir que União, Estados, Distrito Federal e Municípios somem esforços.

Nesse regime de colaboração, as responsabilidades dos entes federados serão diferentes e complementares, e a União continuará a exercer seu papel de coordenação do processo e de correção das desigualdades.

A primeira tarefa de responsabilidade direta da União será a revisão da formação inicial e continuada dos professores para alinhá-las à BNCC. A ação nacional será crucial nessa iniciativa, já que se trata da esfera que responde pela regulação do ensino superior, nível no qual se prepara grande parte desses profissionais. Diante das evidências sobre a relevância dos professores e demais membros da equipe escolar para o sucesso dos alunos, essa é uma ação fundamental para a implementação eficaz da BNCC.

Compete ainda à União, como anteriormente anunciado, promover e coordenar ações e políticas em âmbito federal, estadual e municipal, referentes à avaliação, à elaboração de materiais pedagógicos e aos critérios para a oferta de infraestrutura adequada para o pleno desenvolvimento da educação. Por se constituir em uma política nacional, a implementação da BNCC requer, ainda, o monitoramento pelo MEC em colaboração com os organismos nacionais da área CNE, Consed e Undime. Em um país com a dimensão e a desigualdade do Brasil, a permanência e a sustentabilidade de um projeto como a 
BNCC dependem da criação e do fortalecimento de instâncias técnicopedagógicas nas redes de ensino, priorizando aqueles com menores recursos, tanto técnicos quanto financeiros. Essa função deverá ser exercida pelo MEC, em parceria com o Consed e a Undime, respeitada a autonomia dos entes federados. (BRASIL, 2017, p.21 - grifos próprios)

No que tange a formação continuada de professores, isso fica patente numa lógica que significa a formação à serviço das políticas curriculares. É essa formação - a continuada - que volto minha atenção e esforços de análises na defesa que a submissão da formação às políticas curriculares, como forma de garantia de instituição dessas na prática subtrai da formação sua condição de terreno instável e indecidível de produção docente, advogando então que a formação seja pensada como espaço de reflexão e tradução, na compreensão que venho desenvolvendo sobre isso referenciada nos estudos de Bhabha (2001), que se dá em processos de negociações contínuas que desestabilizam a ideia de fixidez, mas permitem a compreensão do currículo como produção híbrida inacabada, em que a repetição nunca é o mesmo, em sua dimensão performática, mantém vivo e dinâmico o fluxo de significação.

A partir disso, questiono o atrelamento da implementação da política curricular à formação de professores e, em tempos de BNCC, isso se evidencia, fortemente, no Guia de Implementação da Base (BRASIL, 2020) que indica sete dimensões orientadoras no processo de implementação, apresentadas como um percurso de implementação. Dentre essas está a formação de professores para os novos currículos (dimensão 4), cujo “objetivo [desta dimensão] é preparar a coordenação estadual de currículo para o planejamento e execução da formação continuada para os novos currículos de referência, de maneira integrada às ações formativas das redes" (p.36)

Formação continuada para novos currículos: a própria nomeação da dimensão já indica uma significação que retoma o que Canário (2002) aventava como mudança de paradigma, na superação de uma função supletiva que norteava a formação de professores, baseada na ideia de adequação ou adaptação funcional. $\mathrm{O}$ autor indicava, à época, que tais modelos perdiam força diante de um cenário em que:

[...]não é possível continuar a conceber o trabalho humano como algo suscetível de ser objeto de uma descrição fina, a priori, para, em seguida, traduzir essa descrição em termos de estratégias pedagógicas, de objetivos pedagógicos, de conteúdos a ensinar, de gestos a adquirir, de tal modo que os formandos venham a poder encaixar-se nos perfis profissionais previamente definidos. Essa perspectiva de descrição a priori não só não se coaduna como é contraditória com processos de exercício do trabalho que mudam de forma acelerada, adquirindo contornos e configurações que não é possível prever de modo preciso. (CANÁRIO, 2002, p.154) 
Contudo, ao alinhar a formação para novos currículo como percurso de implementação justamente se retoma uma lógica de preditividade da ação docente; a formação reveste-se de um caráter adaptativo, com base numa racionalidade técnica que busca, numa lógica linear e cumulativa, suprir uma falta, essa sim, assumida a priori de que não cabe ao professor a possibilidade de pensar em como desenvolver seu trabalho em diálogo com novas/outras propostas, ou seja, há que se complementar uma falta de qualidade na/da formação inicial, que não provê o docente de condições de reflexão que relacione sua prática com disposições legais/normativas que se apresentam como "novas". Assim, tanto as políticas curriculares quanto a formação se movem e se conectam a partir da falta compartilhada: qualidade, a primeira na intenção de reversão de um quadro de baixo desempenho e fracasso e a segunda como parte desse baixo desempenho.

As políticas curriculares propostas são tomadas como propulsoras de desenvolvimento e mudança, reformando práticas pedagógicas e, por conseguinte, reformando também os professores, para garantir o alcance de tal intento. De forma paradoxal, há uma construção discursiva que, por um lado, deposita nas políticas curriculares o crédito pelas mudanças e relega à formação de professores condição de instrumentalização dessas. Por outro lado, a efetivação da formação de professores também figura como esfera instituinte de políticas curriculares.

Nesse sentido, políticas curriculares e formação de professores são alinhadas como territórios distintos, que pareiam-se em co-dependência para consecução de seus objetivos, mantendo um discurso de adaptação e adequação que uma esfera provoca na outra, dada que, de pontos de observação distintos, voltam-se para a mesma questão: a educação básica.

Esse discurso adaptativo marca as ações que por conta do advento da promulgação da BNCC vem se pondo como tônica das propostas de formação continuada e lançam sua sombra na formação inicial. No processo de discussão que antecedeu a promulgação da Resolução 2/2019 do Conselho Nacional de Educação, que institui a Base Nacional Comum para a Formação Inicial de Professores da Educação Básica - BNC-Formação, a justificativa de sua proposição se assentava na imperiosa necessidade de adequação da formação inicial à BNCC, tal como se pode ver no texto da própria Resolução:

\section{CONSIDERANDO que:}

$\mathrm{O} \S 8^{\circ}$ do art. 62 da LDB estabelece que os currículos dos cursos da formação de docentes terão por referência a Base Nacional Comum Curricular (BNCC-Educação Básica);

A Lei $\mathrm{n}^{\circ}$ 13.415, de 16 de fevereiro de 2017, em seu art. 11, estabelece o prazo de 2 (dois) anos, contados da data de homologação da BNCCEducação Básica, para que seja implementada a referida adequação 
curricular da formação docente; $\mathrm{O} \S 1^{\circ}$ do art. $5^{\circ}$ das Resoluções $\mathrm{CNE} / \mathrm{CP} \mathrm{n}^{\circ}$ 2, de 22 de dezembro de 2017 e CNE/CP no 4, de 17 de dezembro de 2018, entre outras disposições, estabelece que a BNCCEducação Básica deve contribuir para a articulação e a coordenação das políticas e ações educacionais em relação à formação de professores;

As aprendizagens essenciais, previstas na BNCC-Educação Básica, a serem garantidas aos estudantes, para o alcance do seu pleno desenvolvimento, nos termos do art. 205 da Constituição Federal, reiterado pelo art. $2^{\circ}$ da $\mathrm{LDB}$, requerem o estabelecimento das pertinentes competências profissionais dos professores; (BRASIL, 2019, p.115)

Assim, a lógica adaptativa é adensada. Trata-se de uma concepção instrumental de formação inicial que a fragiliza e ao mesmo tempo fortalece uma formação continuada de caráter reparador e supletivo, que parece tornar exigência que a cada nova proposta, a formação seja alvo de ação para adequação/adaptação.

Castro e Amorim (2015) discutem que a reversão de tal paradigma implica no fortalecimento da formação inicial que dê autonomia aos professores de traçarem seus percursos formativos e decidirem como, quando e onde essa formação continuada se dará, além de condições materiais de fazê-lo. Contudo, o que se observa é a manutenção de uma discurso que fomenta a lógica supletiva a partir da crença que os professores não sabem o que fazer na escola sem um currículo comum (LOPES, 2018) ou diante uma nova proposição feita, inclusive que não tem condições de as formularem, o que justifica a forma como os professores são considerados na formulação dessas, especificamente na produção da BNCC, numa participação consultiva não deliberativa.

Retoma-se e mantém-se a dissociação entre produção de políticas e implementação. Assim, o não alcance de mudanças tão como projetado deve-se a questões de ordem prática, de execução e, para dirimir tais problemas, a via possível é a formação continuada. Por implementação entende-se:

Processo de pôr em prática o currículo pretendido ou proposto. No caso de um currículo novo ou revisado, idealmente inclui processos de desenvolvimento e aperfeiçoamento escolar; fomento de liderança e espírito da escola; formação de professores em serviço e desenvolvimento de novos livros didáticos, materiais e recursos de ensino e aprendizagem, bem como orientações. (UNESCO, 2016, p. 56)

Observa-se esse sentido na análise do Guia de Implementação da BNCC (MEC, CONSED, UNDIME et al, 2020) que, no percurso de implementação proposto, tem como quarta etapa a "Formação de professores para um novo currículo":

A partir de 2019, todos os professores terão a oportunidade de serem formados para o trabalho com os novos currículos, elaborados em 
regime de colaboração e norteados pela BNCC. Para isso, a Coordenação Estadual de Currículo deverá estabelecer uma estrutura de formação continuada em regime de colaboração capaz de garantir a implementação dos novos currículos em cada sala de aula. (MEC, CONSED, UNDIME, et al. 2020, p. 36)

Nesse processo, seguindo as orientações dadas no guia às equipes locais, o processo de formação deve ser orientado pelas seguintes questões:

- Quais são as premissas para uma formação continuada que prepare os professores para o desenvolvimento das aprendizagens dos novos currículos?

- Como garantir que as ações formativas alcancem todas as equipes gestoras das escolas e professores das redes?

- Quais são as principais necessidades de professores, equipes gestoras e formadores para a implementação dos novos currículos?

- Como pode ser executada a formação continuada para professores e equipes gestoras, considerando as prioridades das redes e os recursos disponíveis?

- Como promover uma formação continuada em regime de colaboração para os novos currículos que seja integrada e apoie uma revisão das políticas de formação das redes? ((MEC, CONSED, UNDIME et al, 2020, p.37)

Nos questionamentos feitos são apresentadas como demandas para a formação a implementação do novo currículo, como se esse fosse ponto de origem de políticas educacionais cabendo à formação a garantia de operacionalização no cotidiano das escolas da "boa nova" curricular. Nesse sentido, há uma tentativa de controle e regulação que busca fixar sentidos para a docência e para a formação. No caso de propostas de formação continuada, essa se afasta do que autores do campo da formação vem defendendo acerca da noção de formação permanente (IMBERNÓN, 2009), principalmente no que diz respeito a uma formação colaborativa e que responda às demandas dos docentes. Isso implicaria em projetos que se pautassem em perspectivas dialógicas em que o professor, mais que objeto da formação, rompendo com uma lógica transmissiva que se articula a ideia de implementação, fosse assumido como sujeito desse processo.

Acerca da formação, no guia de implementação são indicados como premissas para metodologia e conteúdo das formações:

- FOCO NO DESENVOLVIMENTO DE COMPETÊNCIAS E HABILIDADES: A BNCC representa uma importante mudança na prática de ensino, portanto, a formação deve focar não apenas no conteúdo a ser ensinado, mas também preparar os professores para o desenvolvimento das competências e habilidades, apoiando-os desde o 
processo de planejamento de aulas até o de acompanhamento das aprendizagens dos estudantes nessa nova perspectiva. Afinal, para que os professores possam desenvolver nos estudantes as competências definidas na BNCC, em especial as dez competências gerais, é essencial que tenham a oportunidade de vivenciar uma formação que apoie o seu desenvolvimento nesses aspectos.

- METODOLOGIAS ATIVAS: a formação deve ser significativa para os professores, colocando-os como protagonistas do seu processo de desenvolvimento e contemplando elementos do seu dia a dia de trabalho. Para isso, é possível propor a construção conjunta de planos de aula alinhados ao currículo; a análise da produção dos estudantes como ponto de partida para discussão sobre o processo de ensino e aprendizagem; a observação de sala de aula com devolutivas formativas para o professor; entre outras estratégias. Em suma, a formação deve ser menos baseada na exposição de conhecimento, e mais na construção conjunta, discussão, mudança da prática e na reflexão.

- TRABALHO COLABORATIVO: a colaboração entre professores contribui para a troca de boas práticas e discussões aprofundadas sobre o processo de ensino e aprendizagem dos estudantes. Essa colaboração se torna ainda mais importante no contexto de implementação dos novos currículos, que representam uma mudança para todos os educadores. Essa premissa deve pautar a dinâmica dos encontros de formação, favorecendo que se aprenda por meio do diálogo e da cooperação.

- FOCO EM COMO DESENVOLVER OS CONHECIMENTOS: a formação continuada deve trabalhar três aspectos: I) o conhecimento pedagógico geral (ex: como montar um plano de aula com objetivos claros de aprendizagem); II) o conhecimento do conteúdo em si, em especial quando forem temas que os professores não costumavam trabalhar em determinado ano e/ou componente; e III) o conhecimento pedagógico do conteúdo, ou seja, como os estudantes desenvolvem determinada habilidade e como apoiar esse desenvolvimento através do ensino.

- USO DE DADOS: O uso dos resultados educacionais deve fazer parte da metodologia de formação, para que seja contextualizada e direcionada para as necessidades reais dos professores e dos estudantes. A formação continuada deve apoiar os professores na análise dos resultados educacionais das turmas e no (re)planejamento de aulas à luz do progresso dos estudantes. (MEC, CONSED, UNDIME et al, 2020, p.39)

Ainda que figure nessa indicação a necessidade do trabalho colaborativo e metodologias ativas fazendo referência ao protagonismo do professores, isso se dá como desdobramento do que é posto como foco: as competências da BNCC, um trabalho e protagonismo alinhado ao currículo, esse aprioristicamente estabelecido, assim, trata-se de uma formação que a partir da preditividade como marca, circunscreve o que se espera do professor em termos de adaptação/adequação das práticas. Assim, protagonismo é 
atrelado ao desempenho a ser alcançado, o que adensa discursos de responsabilização docente.

Para o desenvolvimento dessa formação, no guia de implementação ${ }^{2}$, além dessa definição de premissas que garantiriam a qualidade da formação para os novos currículos, é indicado também passos para o desenvolvimento da formação: a definição de governança, a realização de diagnóstico, planejamento da formação, execução da formação, monitoramento da formação, avaliação e replanejamento. (MEC, CONSED, UNDIME et al, 2020)

Acerca do diagnóstico são indicados a observação de três aspectos: as ações formativas já existentes nas redes; os recursos financeiros, materiais e humanos disponíveis nas redes para as formações; e as necessidades formativas de professores, equipes gestoras das escolas e equipes técnicas com relação aos novos currículos.

Há uma seção com recursos para o desenvolvimento das diferentes dimensões e nesse campo há orientações ${ }^{3}$ para a etapa de diagnóstico. Apresentam-se as características gerais de um bom diagnóstico (uso de indicadores objetivos com foco na tomada de decisões e considerando custo-efetividade) e sobre os aspectos a serem considerados são apresentados, em forma de perguntas, percepções sobre cada um desses. Ponho em destaque as questões relativas ao item 3. Necessidades formativas dos professores, equipes gestoras das escolas e equipes técnicas com relação os novos currículos, que traz uma primeira seção de Perguntas: o que se quer descobrir? A que se seguem uma série de questões relativas a resultados educacionais; quantitativo e experiência dos educadores e às demandas com relação aos novos currículos:

\footnotetext{
${ }^{2} \mathrm{O}$ guia é assim descrito: "Para que as aprendizagens propostas pela BNCC cheguem a todos os estudantes, sua implementação precisa ser planejada e acompanhada, com envolvimento de diversos atores e grande mobilização de gestores, técnicos pedagógicos e professores. Essas ações podem e devem começar o quanto antes. A iniciativa do Conselho Nacional de Secretários de Educação (Consed) e da União Nacional dos Dirigentes Municipais de Educação (Undime) busca responder a esse desafio. Como começar o processo? Quem envolver? Como organizar o cronograma, como planejar a comunicação? Para responder a essas e a outras questões foram consultados gestores e técnicos de secretarias estaduais e municipais de todo país, para que as sugestões e orientações contemplassem a realidade e diversidade das redes. Um grupo de trabalho composto por técnicos indicados pelas duas organizações conduziu a produção dos materiais, com o apoio técnico do Movimento pela Base e da Comunidade Educativa - Cedac. Durante a produção, um grupo de 53 coordenadores estaduais da BNCC - um representante da Undime e um do Consed por estado - avaliou a estrutura do Guia e contribuiu para a sua construção. O Guia de Implementação propõe um percurso em 7 etapas, que serão complementadas ao longo do processo, sempre em diálogo com as redes. Não se esqueça de nos enviar seu relato sobre a implementação! Este é um Guia feito por gestores, para você, gestor. Consulte, use, compartilhe. Bom trabalho!" (Disponível no site https://implementacaobncc.com.br/. Acesso em mar/2020) Até o momento estão disponibilizados materiais e orientações até a dimensão 4 - Formação para os novos currículos e há a informação na versão em pdf disponível para download que se trata de versão atualizada em 2020

${ }^{3}$ Elaboradas pelo Grupo de Trabalho de Formação de Professores do Movimento Todos pela Base.
} 
FORMAÇÃO DE PROFESSORES EM TEMPOS DE BNCC: um olhar a partir do campo do currículo

Resultados educacionais

- Quais os resultados de avaliação da aprendizagem dos alunos por ano, componente e regional?

Quantitativo de educadores

- Quantos professores de cada etapa/componente lecionam em cada rede e em cada município?

- Quantos professores trabalham em mais de uma rede ou em escolas particulares?

- Quantos professores são temporários?

- Quantos professores estão em período probatório?

- Há quanto tempo os professores lecionam?

- Com quantos representantes de equipe gestora as escolas contam (ex: diretor, coordenador pedagógico)?

Experiência dos educadores

- Representantes das equipes gestoras das escolas têm atribuições ligadas à formação de professores das escolas?

- Qual percentual de professores com formação inicial ou especialidade nos componentes em que lecionam?

- Quais os resultados de avaliação dos professores (quando houver)?

- Para quantos alunos cada professor leciona?

Demandas com relação aos novos currículos

- Quais as principais mudanças trazidas pelo novo currículo com relação ao currículo vigente que deverão impactar a prática dos professores?

- Qual o conhecimento prévio dos formadores, equipes gestoras e professores sobre a BNCC e os novos currículos?

- Quais são as principais demandas dos formadores, equipes técnicas, equipes gestoras e professores como relação à formação para os novos currículos? (MOVIMENTO PELA BASE, 2019, p. 4).

O documento orientador traz, ainda no item 3. Necessidades formativas dos professores, equipes gestoras das escolas e equipes técnicas com relação os novos currículos, uma segunda seção Justificativa: como essas perguntas orientam a tomada de decisão? com as indicações:

Os dados sobre "resultados educacionais" ajudam a na tomada de decisão sobre os temas a serem priorizados na formação. Por exemplo: caso os resultados de alfabetização, ou matemática no Ensino Fundamental, sejam os mais preocupantes, esses devem contar com uma maior dedicação de tempo na formação. 
Os dados sobre o "quantitativo de educadores" ajudam a compreender o tamanho da demanda por formação. Essa informação, contrastada com os recursos disponíveis nas redes (ex: número de formadores) ajuda a dimensionar os esforços e a compreender se será necessário contar com parcerias externas para executar a formação.

Os dados sobre a "experiência dos educadores" ajudam a ter mais clareza do público-alvo das formações e do tipo de atividade que poderia melhor se adequar às suas necessidades. Além disso, ajudam a identificar oportunidades como: tutoria de professores mais experientes para professores menos experientes; agrupamentos para grupos de estudos; etc. Dois indicadores que podem ser importantes para um diagnóstico do perfil dos educadores são o Ciclo de Vida Profissional e o Indicador de Esforço Docente.

As informações sobre as "demandas com relação aos novos currículos" ajudam a compreender o ponto de partida dos educadores das redes com relação àquilo para o que têm que ser formados. Por exemplo: um corpo docente que participou ativamente da construção do currículo precisa de menos contextualização sobre esse processo do que um que não acompanhou a (re)elaboração curricular. (MOVIMENTO PELA BASE, 2019, p. 4-5).

Chama atenção que as necessidades formativas são reguladas pelo desempenho dos alunos e as demandas são projetadas a partir dos novos currículos. Na verdade, a ideia de demanda aqui pode ser lida como necessidades de mudança para configurar o novo currículo. É do currículo, tomado como coisa, estabelecido e estável, que se desdobram exigências para sua materialização. Tem-se de tal modo uma leitura polarizada entre prescrições curriculares e a prática cotidiana (a ser alterada) como entidades fixas. Tal apreensão é que imputa à formação feições instrumentais e, assim sendo, bloqueia sentidos que possam entende-la, tal como defendo acerca das políticas curriculares, como instituída e atravessada por múltiplas significações discursivas, hegemônicas e nãohegemônicas, e que no seu interior, a diferença se move identificada por demandas contingentes, que produzem articulações provisórias. Há um silenciamento sobre as experiências, práticas, conflitos e demandas que as diferentes redes de ensino/escolas/professores tem, fazem, constroem; uma tentativa de fechamento de sentido que tenta - porque essa tentativa sempre é fracassada - fixar sentidos a serem reproduzidos, solapando as possibilidades de articulação entre/com diferentes contextos de produção.

É no ato de negociar que significados são construídos dialogicamente, se constituindo com base em consensos conflituosos, uma vez que os sentidos são instáveis, fluidos e permeados por demandas e interesses distintos. 
Contudo, o delineamento dado põe a seta indicando uma única direção possível, demarca uma sequência de ação cujos esforços envidados objetivam a implementação do currículo no cotidiano, à sua imagem e semelhança, passível de totalização.

\section{Formação de professores e políticas curriculares - E se a relação fosse outra?}

Mera ilusão auditiva graças à qual a gente ouve sempre "tic-tac" e nunca "tac-tic". Despois disso, como acreditar nos relógios? Ou na gente?

Mario Quintana

A problematização que trouxe, a partir de análise que põe em diálogo o campo do currículo e da formação de professores em sua imbricada relação, intenta inquirir: e se a relação fosse outra?

É preciso advertir que a busca por outra relação não significa aqui a inversão de polos, o que manteria a ordem binária e dicotomizada que busquei evidenciar e discutir. Ao contrário, a intenção é desestabilizar significações de forma a possibilitar a emergência de outros/novos e sempre precários, num movimento incessante de produção significação. É ressignificação de políticas curriculares e formação de professores em sua condição produção híbrida, negociada e impossível de sedimentar, de uma vez por todas, sentidos para o currículo e a docência. Assim, trata-se de perceber políticas curriculares como negociações no jogo político como luta pela significação. Mais que determinar lugares próprios, formação e currículo vistos como rastros, elaborações num entre-lugar (BHABHA, 2001) decisório que, riscando a fronteira delimitadora, constituem-se como ambivalência e na alteridade.

\section{Referências}

ABRIC, J. C. A abordagem estrutural das representações sociais. In: MOREIRA, Antonia Silva Paredes; OLIVEIRA, Denize Cristina (Org.). Estudos interdisciplinares de representação social. Goiânia: AB, 2000. p. 27-38.

BALL, S. Education reform - a critical and post structural approach. Philadelphia: Open University Press, 1997.

BALL, S. Como as escolas fazem política - atuação em escolas secundárias. Ponta Grossa: Editora UEPG, 2016.

BHABHA, H. O local da cultura. Belo Horizonte: Editora UFMG,2001. 
BRASIL. Resolução n ${ }^{\circ}$ 2, de 20 de dezembro de 2019. Define as Diretrizes Curriculares Nacionais para a Formação Inicial de Professores para a Educação Básica e institui a Base Nacional Comum para a Formação Inicial de Professores da Educação Básica (BNCFormação). Diário Oficial da União, n 247, 23 de dezembro de 2019. Seção I, p.115119.

CANÁRIO, R.; PIRES, C. M. C.; HADJI, C. Articulação Entre As Formações Inicial e Continuada de Professores. In: Congresso Brasileiro de Qualidade na Educação: Formação de Professores, 1, 2002, Brasília. Anais [...]. Brasília, DF: MEC/SEB, 2002. P. 151-174.

CASTRO, M. C.; AMORIM, R. M. A. A formação inicial e a continuada: diferenças conceituais que legitimam um espaço de formação permanente de vida. Cadernos Cedes. Campinas, v. 35, n. 95, p. 37-55, jan.-abr., 2015

DIAS, R. E.; FRANGELLA, R. C. Os sentidos de docência na BNCC: efeitos para o currículo da educação básica e da formação/atuação de professores. Educação Unisinos (Online), v. 22, p. 7-15, 2018.

FRANGELLA, R. C. Políticas de Currículo e Alfabetização: Negociações Para Além de um Pacto. Projeto de pesquisa. Rio de Janeiro: UERJ, 2016a

FRANGELLA, R. C. Políticas de formação do alfabetizador e produção de políticas curriculares: pactuando sentidos para formação, alfabetização e currículo. Ponta Grossa: Práxis Educativa, v. 11, n. 1, p. 107-128, jan./abr. 2016b

FRANGELLA, R. C. Políticas de currículo, alfabetização e infância: entre paradoxos e antíteses, renegociando o $(s)$ pacto $(s)$. Projeto de pesquisa. Rio de Janeiro: UERJ, 2019.

IMBERNÓN, F. Formação permanente do professorado: Novas tendências. $1^{\circ}$ ed. São Paulo: Ed. Cortez, 2009.

LOPES, A. C. Apostando na produção contextual do currículo. IN: AGUIAR, Márcia Ângela da S. e DOURADO, Luiz Fernandes (orgs.) A BNCC na contramão do PNE 20142024: avaliação e perspectivas. Recife: ANPAE, 2018. [Livro Eletrônico]

MACEDO, E. Base nacional curricular comum: a falsa oposição entre conhecimento para fazer algo e conhecimento em si. Educação em revista, Belo Horizonte, v. 32, n. 2, p. 4568, jun 2016.

MEC, CONSED, UNDIME, UNCME, FNCEE. Guia de implementação da Base Nacional Comum Curricular - orientações para o processo de implementação da BNCC. 2020. Disponível em: https://implementacaobncc.com.br/wp-content/uploads/2020/02/ guia implementacao_bncc_atualizado_2020.pdf,.Acesso em mar/2020.

MOVIMENTO PELA BASE. Orientações para a Etapa de Diagnóstico da Formação Continuada para os novos currículos. Grupo de Trabalho de Formação de Professores do 
FORMAÇÃO DE PROFESSORES EM TEMPOS DE BNCC: um olhar a partir do campo do currículo

Movimento pela Base. 2019. Disponível em http://movimentopelabase.org.br/wpcontent/uploads/2019/01/2018_12_MPB-diagnostico_v03.pdf Acesso em mar/2020.

MORAES, V. A Arca de Noé. São Paulo: Cia das Letrinhas, 2010.

QUINTANA, M. Caderno H. São Paulo: Editora Globo, 2ª Ed, 2006.

UNESCO. Glossário de Terminologia Curricular. Bureau Internacional de Educação da UNESCO (UNESCO-IBE), 2016. Disponível em: https://unesdoc.unesco.org/ark:/ 48223/pf0000223059_por Acesso em mar/2020.

Recebido em: 21 mar. 2020. Aprovado em: 11 jun. 2020.

* Rita de Cássia Prazeres Frangella é Professora associada da Faculdade de Educação e do Programa de Pós-Graduação em Educação (PROPED) da UERJ. Coordenadora de área/Educação da Fundação de Amparo à Pesquisa do Estado do Rio de Janeiro/FAPERJ Coordena o Grupo de Pesquisa Currículo, formação e educação em direitos humanos. É Bolsista de Produtividade do CNPq, Jovem Cientista do Nosso Estado da FAPERJ e PROCIENTISTA/UERJ. Presidente da Associação Brasileira de Currículo (ABdC) no período 2019-2020.

E-mail: rcfrangela@gmail.com

https://orcid.org/0000-0001-6392-4591 